\title{
Intra-Arterial Thrombolysis for Central Retinal Artery Occlusion
}

This article was published in the following Dove Press journal:

Clinical Ophthalmology

\author{
Navid Hakim (D) \\ Jamil Hakim ${ }^{2}$
}

'St. Pauls Eye Department, Royal Liverpool Hospital, Liverpool, UK; ${ }^{2}$ Ophthalmology Department, Queen Mary's Hospital Sidcup, Sidcup, UK
Correspondence: Navid Hakim St. Pauls Eye Department Royal Liverpool Hospital Prescot St, Liverpool L7 8XP, UK Tel +07540492816

Email navid.hakim@nhs.net
Introduction: Central retinal artery occlusion is an ophthalmic emergency which typically causes acute, painless visual loss. Several conservative treatment options are practiced with little benefit. Thrombolysis as a therapeutic option has gathered interest as well as controversy. This paper aims at reviewing the relevant literature to assess the efficacy and safety of intra-arterial thrombolysis for acute central retinal artery occlusion.

Methods: A review of the literature was conducted. Keywords included "intra-arterial thrombolysis" or "intra-arterial fibrinolysis" in combination with "central retinal artery occlusion" or "CRAO". A Cochrane Database search was performed for randomised control trials, systematic reviews and meta-analyses using the same keywords.

Results: Twenty-eight studies were identified which included case reports, case series, casecontrol studies and 1 randomised control trial: the European Assessment Group for Lysis in the Eye Study. Improvement in vision was measured using different methods and at different time points. The findings of these studies generally favour an effect towards intra-arterial thrombolysis however there are many limitations. Additionally, the European Assessment Group for Lysis in the Eye Study showed lack of effect in intra-arterial thrombolysis vs conservative measures.

Conclusion: Current evidence is not sufficient to recommend intra-arterial thrombolysis due to the variability of visual improvement within retrospective studies, heterogeneity in treatment regimens between studies and adverse effects. Intra-arterial thrombolysis may have a role in patients presenting early, particularly if they have monocular vision, after discussion of the risks and benefits. Further high-quality trials assessing the clinical efficacy of intraarterial thrombolysis may shed more light on this topic.

Keywords: central retinal artery occlusion, intra-arterial, thrombolysis, fibrinolysis

\section{Introduction}

Central retinal artery occlusion (CRAO) is an ophthalmic emergency which causes acute, painless visual loss. It was first described by von Graefes in 1859 as an embolus to the central retinal artery (CRA) causing sudden blindness. ${ }^{1}$ CRAO has an estimated incidence of $1-2$ per 100,000 and is bilateral in $1-2 \%$ of cases. ${ }^{2,3}$ Diagnosis is often on clinical examination and investigations are seldom required. Management on the other hand is less straightforward. Several conservative treatment options are practiced including ocular massage, anterior chamber paracentesis and intravenous acetazolamide. ${ }^{4-6}$ Unfortunately, all conservative options have been shown to have limited efficacy. ${ }^{4}$ Thrombolysis is a therapeutic option which aims at dissolving the embolus. This stems from the proven efficacy of thrombolysis for other thromboembolic conditions such as ischaemic heart disease and acute ischaemic 
stroke. ${ }^{7}$ As a therapeutic option, it has gathered interest as well as controversy. Both intravenous and intra-arterial routes have been practiced, ${ }^{7,8}$ each with their respective benefits and risks. Intra-arterial thrombolysis (IAT) by selective microcatheter catheterization of the ophthalmic artery (OA), though more invasive than the intravenous route, has been investigated for over 20 years due to potentially improved visual outcomes with reduced systemic complications. ${ }^{9}$ The results of the few studies on IAT are inconsistent and much of the supporting evidence comes from retrospective case series. ${ }^{10-12}$ The only randomised control trial, the European Assessment Group for Lysis in the Eye (EAGLE) study, ${ }^{13}$ did not find any statistically significant improvement in final visual outcome in patients who underwent IAT compared to standard therapy but reported a higher rate of complications within this group. However, the validity of this clinical trial has been questioned due to potential flaws in study design. ${ }^{14}$ Further reports have emerged since favouring the effectiveness of this therapeutic option. As such, this paper aims at reviewing the available relevant literature to assess the efficacy and safety of IAT for acute CRAO.

\section{Background}

CRAO presents as acute, painless visual loss typically in patients above the age of 50 . Visual loss is rarely complete blindness with up to $75 \%$ of patients having a visual acuity (VA) of counting fingers (CF). ${ }^{15}$ The typical acute fundus findings are retinal opacification, a cherry-red spot, sludging of red blood cells, venous attenuation, and optic disc pallor (Figure 1). ${ }^{16}$ Late changes include retinal pigment epithelial changes, sheathed arteries, attenuated veins, optic disc atrophy and cilioretinal collaterals. ${ }^{16}$

Embolism is the most common cause of central retinal artery occlusion (CRAO) and two-thirds of cases are caused by emboli secondary to atherosclerosis of the internal carotid artery (ICA). ${ }^{17}$ Plaque in the ICA is the most common source of microemboli. ${ }^{18}$ The three commonest types of visible emboli are cholesterol, platelet-fibrin and

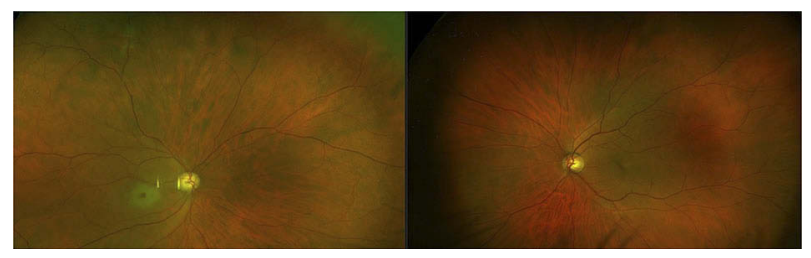

Figure I Widefield imaging showing classical features of CRAO: pale retina with a cherry-red spot in the right eye. calcific emboli. Embolus composition is important with respect to thrombolytic therapy as only platelet-fibrin emboli would be susceptible to it. Historically, cholesterol emboli were shown to be the most common type in a study by Arruga et al ${ }^{19}$ of 70 patients with retinal embolism which showed that $57 \%$ were cholesterol, $11 \%$ plateletfibrin and approximately 9\% calcific. However, the commonest location of occlusion is at the narrowest part of the CRA lumen where it enters the dural sheath of the optic nerve $^{20}$ and thus this may not be representative of retrobulbar emboli.

As in acute ischaemic stroke and myocardial infarction, the time following CRA occlusion is crucial in determining the survival of retinal tissue. The retinal tolerance time to acute ischaemia in human eyes has been estimated from animal studies in rhesus monkeys. Initial studies on young rhesus monkeys showed mild posterior retinal opacification and disc pallor at 7 mins after CRAO progressing to marked opacification from 24 to $60 \mathrm{mins}$ and severe opacification at 60 mins. $^{21}$ After removal of occlusion, the retina recovered at a duration of 97 mins of ischaemia and suffered irreparable damage after 105 mins of ischaemia. Histology confirmed irreversible damage to the inner retina with preservation of the photoreceptor and outer retina, and the macula was observed as the most susceptible area to ischaemia. This experiment was reproduced on older rhesus monkeys in which atherosclerosis and chronic arterial hypertension were induced to study conditions more alike that in elderly patients with these comorbidities. $^{22}$ Fundus fluorescein angiography (FFA) showed that vascular anastomoses allowed the retinal vasculature to fill very slowly despite complete occlusion. Complete or near complete loss of visibility of the retinal nerve fibre layer and optic disc pallor was observed in all eyes occluded for 240 mins or longer. No apparent optic nerve damage was observed in occlusion of less than 100 mins. Due to the similarities between rhesus monkey eyes and human eyes, and taking into account functional visual loss tends to occur earlier than anatomic loss, Hayreh et al concluded that irreversible damage to the retina from ischaemia likely occurs in less than $4 \mathrm{hrs}$ from onset. ${ }^{22}$ This was later confirmed in a meta-analysis by Schrag et al who found that systemic thrombolysis was beneficial at $4.5 \mathrm{hrs}$ or earlier from symptom onset. ${ }^{23}$

\section{Diagnosis}

Diagnosis is often on clinical examination and investigations are rarely required. Direct visualisation of the 
embolus confirms a thromboembolic cause and is sometimes possible either at the disc or in a branch retinal artery. Cholesterol emboli are described as yellow, orange or copper bodies which are globular or rectangular in shape; platelet-fibrin emboli are dull grey-white plugs that are usually mobile and calcific emboli are solid white ovoid-shaped bodies. ${ }^{19}$ The absence of a visible embolus does not exclude embolism as the majority of emboli are retrobulbar and due to the tendency of emboli to migrate within the retinal circulation. ${ }^{18}$

Investigations can be performed if there is uncertainty regarding the diagnosis. FFA can be performed and typically shows delayed or restricted filling of the retinal arterioles. ${ }^{24}$ Optical coherence tomography (OCT) can be performed to assess the thickness of the retina. Increased reflectivity and thickness of the inner retina are observed in the acute phase and (Figure 2), conversely, in the late phase, there is decreased reflectivity and thickness due to atrophy of the neurosensory retina. ${ }^{25}$

\section{Classification}

CRAO can be classified into 4 different types which is important with regards to management and visual prognosis.

\section{Non-Arteritic CRAO (NA-CRAO)}

NA-CRAO is the most common type of CRAO occurring in approximately $65 \%$ of patients ${ }^{26}$ and is analogous to acute ischaemic stroke of the retina. Patients with NACRAO present with the typical symptoms of sudden severe monocular visual loss and have the characteristic findings of pale retina with a cherry-red spot.

\section{Non-Arteritic CRAO with Cilioretinal Sparing}

Cilioretinal arteries originate from the posterior ciliary arteries and are therefore spared in CRAO. They can contribute towards macular perfusion thus the presence of a cilioretinal artery can be favourable due to preservation of central vision. A prospective study of 2000 eyes found that $32.1 \%$ of eyes had a cilioretinal artery and $14.6 \%$ occurred bilaterally. ${ }^{27}$ These contributed to the macular circulation in

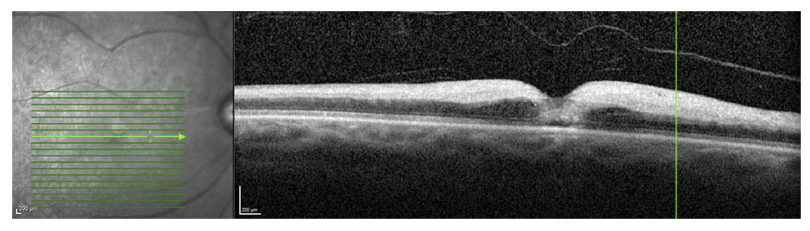

Figure 2 OCT image showing hyperreflectivity and increased thickness of the inner retina in CRAO.
$18.7 \%$ of patients and VA may be preserved at 20/50 or better with loss of peripheral vision only. ${ }^{28}$ VA can however vary due to the variability in size of the cilioretinal artery and the area supplied. ${ }^{15}$ Cilioretinal arteries are also at risk of occlusion due to a lower perfusion pressure compared to the CRA.

\section{Transient Non-Arteritic CRAO}

Transient non-arteritic CRAO occurs in approximately $15 \%$ of patients ${ }^{26}$ and presents with reversible visual loss lasting minutes to hours. It can occur in the context of haemodynamic ischaemia such as in nocturnal arterial hypotension or if the embolus has cleared the retinal circulation. Another cause of this condition is transient vasospasm due to serotonin release from platelets on atherosclerotic plaques. ${ }^{18}$ Though patients with transient non-arteritic CRAO have a more favourable prognosis, they are at a high risk of ischaemic events including NA-CRAO, cerebral infarction, myocardial infarction and vascular death. ${ }^{6}$

\section{Arteritic CRAO}

Arteritic CRAO occurs in less than $5 \%$ of patients ${ }^{26}$ and occurs most commonly due to giant cell arteritis (GCA). Non-arteritic anterior ischaemic optic neuropathy can also occur concurrently and thus visual loss can be profound due to the combination of infarction of the retina with ischaemia to the optic nerve. As such, the mainstay of management of arteritic CRAO is with corticosteroids.

\section{Management}

There is no consensus on the management of CRAO. A survey by Youn et $\mathrm{al}^{29}$ of 43 university hospitals showed that $20 \%$ of programs had a formal approach to the management of CRAO, 33\% of programs indicated there was no consensus within their own department, and $9 \%$ opposed using any treatments due to their lack of efficacy.

Various acute treatment options have been proposed and practiced (Table 1). ${ }^{4}$ Unfortunately, none of these have proven efficacious. A Cochrane review by Fraser et $\mathrm{al}^{4}$ on interventions for acute NA-CRAO found only 2 randomised controlled trials (RCTs) that met the inclusion criteria: one study on pentoxifylline and the other on enhanced external counter pulsation. Though the results of these studies showed improvement in retinal perfusion in the intervention groups, there was no improvement in vision. ${ }^{4}$

The interest for thrombolysis as a therapeutic agent in CRAO stems from the proven efficacy of thrombolysis in ischaemic heart disease $\mathrm{e}^{31}$ and acute ischaemic stroke ${ }^{32}$ and the similarities between these conditions and CRAO.,33 
Table I A Summary of Current Conservative Treatment Options and Their Mechanism of Action. 4,6,30

\begin{tabular}{|c|c|}
\hline \multicolumn{2}{|l|}{ Conservative Treatment Options for CRAO } \\
\hline Treatment Option & Possible Mechanism of Action \\
\hline Sublingual isosorbide dinitrate & Dilation of retinal vasculature thus increased perfusion into the retinal artery \\
\hline Carbogen inhalation & $\begin{array}{l}\text { Inhalation of this mixture of } 95 \% \text { oxygen and } 5 \% \text { carbon dioxide to increase blood carbon } \\
\text { dioxide concentration preventing oxygen-induced vasoconstriction thus allowing increased } \\
\text { perfusion to retinal tissue }\end{array}$ \\
\hline Hyperbaric oxygen & $\begin{array}{l}\text { Inhalation of hyperbaric oxygen to increase oxygen tension and oxygen delivery to ischaemic } \\
\text { retinal tissue }\end{array}$ \\
\hline Ocular massage & $\begin{array}{l}\text { Digital compression of the globe to mechanically dislodge the embolus allowing it to pass } \\
\text { through the retinal circulation }\end{array}$ \\
\hline Anterior chamber paracentesis & $\begin{array}{l}\text { Withdrawal of } 0.1-0.2 \mathrm{~mL} \text { of aqueous fluid to reduce intra-ocular pressure (IOP) and allow an } \\
\text { increase in perfusion pressure }\end{array}$ \\
\hline IV acetazolamide & \multirow[t]{2}{*}{ IV infusion to reduce intra-ocular pressure (IOP) to allow an increase in perfusion pressure } \\
\hline IV mannitol & \\
\hline Pentoxifylline & $\begin{array}{l}\text { Reduction of red blood cell rigidity allowing them to pass through capillaries with greater ease } \\
\text { and a reduction of blood viscosity }\end{array}$ \\
\hline Systemic steroids & Reduction in vascular endothelial oedema \\
\hline Enhanced external counter pulsation & $\begin{array}{l}\text { Sequential inflation of pneumatic cuffs around the lower extremities at diastole to increase } \\
\text { venous return and at the onset of systole to decrease systolic pressure causing increased blood } \\
\text { flow }\end{array}$ \\
\hline $\begin{array}{l}\text { Neodymium-doped yttrium aluminium garnet } \\
\text { (Nd:YAG) laser embolectomy }\end{array}$ & Nd:YAG laser to dislodge embolus \\
\hline
\end{tabular}

Based on the same principle, the theoretical basis is that thrombolysis could restore retinal blood flow in CRAO by dissolving occlusive thromboemboli and prevent ischaemic damage. ${ }^{11}$ Consequently, thrombolysis would not be effective in non-embolic causes such as CRA dissection.

\section{Intravenous Thrombolysis}

The IV route is quick and easy to administer, and many facilities will already have the existing infrastructure for use in acute ischaemic stroke and myocardial infarction. A review by Biousse et $\mathrm{al}^{33}$ showed that $48.5 \%(\mathrm{n}=50)$ of patients with acute CRAO had obvious improvement of VA and these results appeared better than that with conservative measures and the natural history of CRAO. However, due to the larger doses required and systemic distribution of the thrombolytic agent, there is an increased risk of systemic complications. Consequently, there are many contraindications to thrombolysis. These were originally developed during the National Institute of Neurological Disorders and Stroke rt-PA Stroke Study Group (NINDS) stroke trial to identify the ideal patient for thrombolysis and it has been argued that they are outdated and may be restricting the number of potential patients from treatment. $^{34}$ As such, IAT has been pursued as only one occluded vessel needs to be treated through selective catheterization and infusion of thrombolytic into the OA thereby avoiding systemic administration.

\section{Intra-Arterial Thrombolysis}

IAT was pioneered by Schumacher and Schmidt in the early 1990s. ${ }^{35}$ A microcatheter was placed in the proximal portion of the OA through a femoral approach and thrombolytic administered. Following this, several case reports were published throughout the 1990s in favour of IAT for CRAO. ${ }^{36}$ The method of selective catheterisation of the affected vessel with localised infusion of the thrombolytic agent requires a smaller dose of thrombolytic to achieve a high local concentration. ${ }^{34}$ However, IAT also has its drawbacks: it is not as easily performed and requires a multispecialist approach including early diagnosis of CRAO, interventional neuroradiology services and careful 
inpatient monitoring of vital functions and coagulation factors during and after treatment. ${ }^{14}$ These services are unlikely to be available in most hospitals.

\section{Complications}

The most important complication of thrombolysis is haemorrhage. The NINDS trial ${ }^{32}$ of 291 patients identified symptomatic intracranial haemorrhage within $36 \mathrm{hrs}$ of treatment in $8 \%$ of the thrombolysis treatment group of which $4 \%$ was fatal compared with no events in the control group. Additionally, 3\% of patients in the treatment group had asymptomatic intracranial haemorrhage within $36 \mathrm{hrs}$ of treatment and a further $3 \%$ of the treatment group developed symptomatic intracranial haemorrhage on long-term follow-up. Consequently, thrombolysis is contraindicated in patients with underlying conditions that may have devastating consequences in the event of a bleed. These include myocardial infarction, cardiac aneurysm, haemorrhagic diathesis, liver cirrhosis, gastric ulceration, untreatable hypertension and oral anticoagulation use. ${ }^{12}$

\section{Prognosis}

Visual prognosis in patients after CRAO was evaluated in a prospective study of 244 patients ${ }^{15}$ which showed variability in initial and final VA depending on the type of CRAO. Initial VA was $20 / 40$ or better in $37.9 \%$ of eyes with transient NA-CRAO, $20 \%$ of eyes with NA-CRAO with cilioretinal artery sparing and in $0 \%$ of eyes with NACRAO and arteritic CRAO. Seventy-four percent of eyes presented with an initial VA of CF or worse. Patients with transient NA-CRAO had a better initial VA, 37.9\% had CF compared with $93.2 \%$ of NA-CRAO, and a higher proportion also showed greater visual improvement: $82 \%$ compared with $22 \%$ in NA-CRAO.

Visual field (VF) defects were noted: central scotoma was the most common scotoma and generalised constriction of the VF the most common defect in transient NA-CRAO (17.1\% of eyes) and NA-CRAO with cilioretinal artery sparing (32.3\% of eyes). In NA-CRAO, $51.9 \%$ of eyes had only a peripheral island residual field, most frequently in the temporal region. Improvement in VFs was seen in all types of CRAO and recovery to normal VFs was observed in some patients with transient NA-CRAO. Both VA improvement with central VFs improvement was observed in $30 \%$ of eyes with transient NA-CRAO, $25 \%$ of NA-CRAO with cilioretinal sparing, and only $6 \%$ with NA-CRAO. Though patients with transient non-arteritic CRAO have a better visual prognosis, they are at a high risk of ischaemic events including NA-CRAO, cerebral infarction, myocardial infarction and vascular death. ${ }^{6}$

Neovascularisation due to retinal ischaemia can lead to further visual loss and has been estimated between $2.5 \%$ and $31.6 \%$ of patients with CRAO. This may subsequently lead to neovascular glaucoma, intraocular haemorrhage or tractional retinal detachment. ${ }^{37}$ Patients with CRAO have silent or other infarcts visible on MRI in $25 \%$ of patients. ${ }^{38}$ In patients without a history of stroke, the risk of stroke following CRAO is increased to between $4.8 \%$ and $35.5 \%$ within 3 years following ocular diagnosis. ${ }^{39}$

\section{Methods}

A review of the literature was conducted to assess the published evidence on thrombolysis in CRAO. A structured search of the MEDLINE online database was performed. Keywords included "intra-arterial thrombolysis" or "intraarterial fibrinolysis" in combination with "central retinal artery occlusion" or "CRAO". Relevant articles were reviewed for content and overall significance. The inclusion criteria for studies were English language case reports, case series and RCTs of patients with acute onset NA-CRAO who underwent IAT. Studies reporting on patients who had more than one acute pathology (central retinal vein occlusion as well as CRAO) that might contribute towards visual loss were excluded as well as if more than one technique was used (Nd:YAG laser in the combination of IAT). The references of all articles were assessed to obtain further studies relevant to the subject. A Cochrane Database search was also performed for RCTs, systematic reviews and meta-analyses using the same keywords. Information including VA, time between onset of symptoms and thrombolysis, pre-procedure angiogram findings, thrombolytic agent and dosage of thrombolysis, post-procedure imaging, adverse effects and final visual outcome was recorded.

\section{Results}

Literature review identified 28 studies which include case reports, case series, case-control studies and 1 RCT. Vision was measured using VA from Snellen charts and the logarithm of the minimal angle of resolution (logMAR) acuity using standardised notation however different end points were used. If patients were unable to visualise the chart, vision was recorded according to whether they could count fingers (CF), see hand movements (HM) or whether they had light perception (PL). 


\section{Case Reports}

Twelve case reports were included ${ }^{40-48}$ (Table 2). Four additional case reports are reported separately as these patients developed CRAO during or post-procedure (Table 3).

\section{Improvement in VA and Time to Treatment}

The delay to treatment varied from 4 to $<24 \mathrm{hrs}$. Only 3 patients had IAT within $6 \mathrm{hrs}$ and all of these patients recovered normal VA. Two of these patients also recovered normal VFs. One patient had IAT at $6.5 \mathrm{hrs}$ and had partial recovery of vision. The time to treatment was significantly higher in the other 8 patients ranging from 10 to $<24 \mathrm{hrs}$. Four of these patients had a significantly better final VA: 1 patient achieved normal VA and VFs; 1 patient recovered to 6/9 (however significant restriction of peripheral VFs was present); 1 patient recovered to $20 / 25$ and 1 patient achieved 20/70 after presenting with VA $1 / 200$. It is interesting to note that one of these patients where IAT was performed at $13.5 \mathrm{hrs}$ recovered normal VA and VFs. FFA post-IAT confirmed recanalization in 3 of these patients and was not reported in 1 case. Of the remaining 4 patients, 2 improved from LP to HM and the other 2 did not have any improvement.

Recanalization on post-procedure FFA was seen in all 3 patients who had IAT within $6 \mathrm{hrs}$ and in 3 other patients (not reported in 1 case). In patients who did not make a significant visual recovery, the typical chronic findings of CRAO of retinal atrophy were observed on OCT.

\section{Classification and Embolus Composition}

Arteritic CRAO was excluded in 6 cases $^{41,44,45,47,48}$ based on reported history (arteritic symptoms excluded) and investigations (normal CRP and ESR). Embolus composition was only mentioned in 1 case $^{41}$ where Hollenhurst plaques were observed and this patient achieved VA of 20/ 20 after IAT. There was no atherosclerotic lesion, thrombus or steno-occlusive lesion found on pre-procedure angiography in all cases where reported.

\section{Technique and Dosage}

The majority of investigators reported using a microcatheter placed in the proximal segment of the OA. Various different treatment regimens were followed: Seven of the investigators used urokinase, dose ranging from 40,000 to 900,000 units; rTPA was used in 3 cases, dosage of 40 to $70 \mathrm{mg}$; alteplase was used in 1 case. Other agents were also given including systemic heparinisation, abciximab, tirofiban and verapamil.

\section{Complications}

No complications were reported in any of the 12 patients.

\section{Post-Procedure Case Reports}

Four case reports of iatrogenic causes of CRAO were found $^{49-52}$ (Table 3). These were managed with similar techniques of microcatheter insertion into the $\mathrm{OA}$ and thrombolytics injected were urokinase and rTPA. Postprocedure angiographic imaging was possible in these cases and showed improved retinochoroidal blush and restoration of blood flow. Despite the time to treatment being significantly lower in these cases (under $3 \mathrm{hrs}$ ) and restoration of blood flow, improvement in vision was poor: only 1 patient achieved a normal VA, 1 patient achieved 20/30 from LP, and 2 patients achieved CF from LP.

\section{Case Series}

Six retrospective case series were included which investigated IAT in 174 patients $^{53-58}$ (Table 4).

\section{Improvement in VA and Time to Treatment}

There was an improvement of VA from initial VA in between $26 \%$ and $66 \%$ of patients within these studies. Complete or marked recovery was observed in some patients. There was heterogeneity in the definition of improvement in VA. This was measured as the improvement from initial VA, improvement of lines on Snellen chart, improvement of VA $>0.3 \log$ MAR and actual VA improvement. Schumacher et $\mathrm{al}^{53}$ reported "marked" and "definite improvement" and Mercier et $\mathrm{al}^{58}$ reported a "significant" improvement but the authors did not define these terms. Three investigators did not find a significant difference between time delay and improved visual outcome. Of note, the mean time to treatment was $34.6 \mathrm{hrs}$ in one study ${ }^{53}$ and $74 \%$ of patients still gained a marked or definite improvement.

\section{Classification and Embolus Composition}

Cilioretinal arteries were reported in one study. ${ }^{56}$ Arteritic CRAO was excluded in 2 studies. ${ }^{54,56}$ Richard et al $^{54}$ noted that a platelet-fibrin embolus was detectable in 6 patients and found no significant difference in visual outcome between these patients and in those without plateletfibrin emboli however these may have not been detectable in all patients.

\section{Technique and Dosage}

Overall IAT techniques were comparable with microcatheter placement at or within the OA. Thrombolytics 


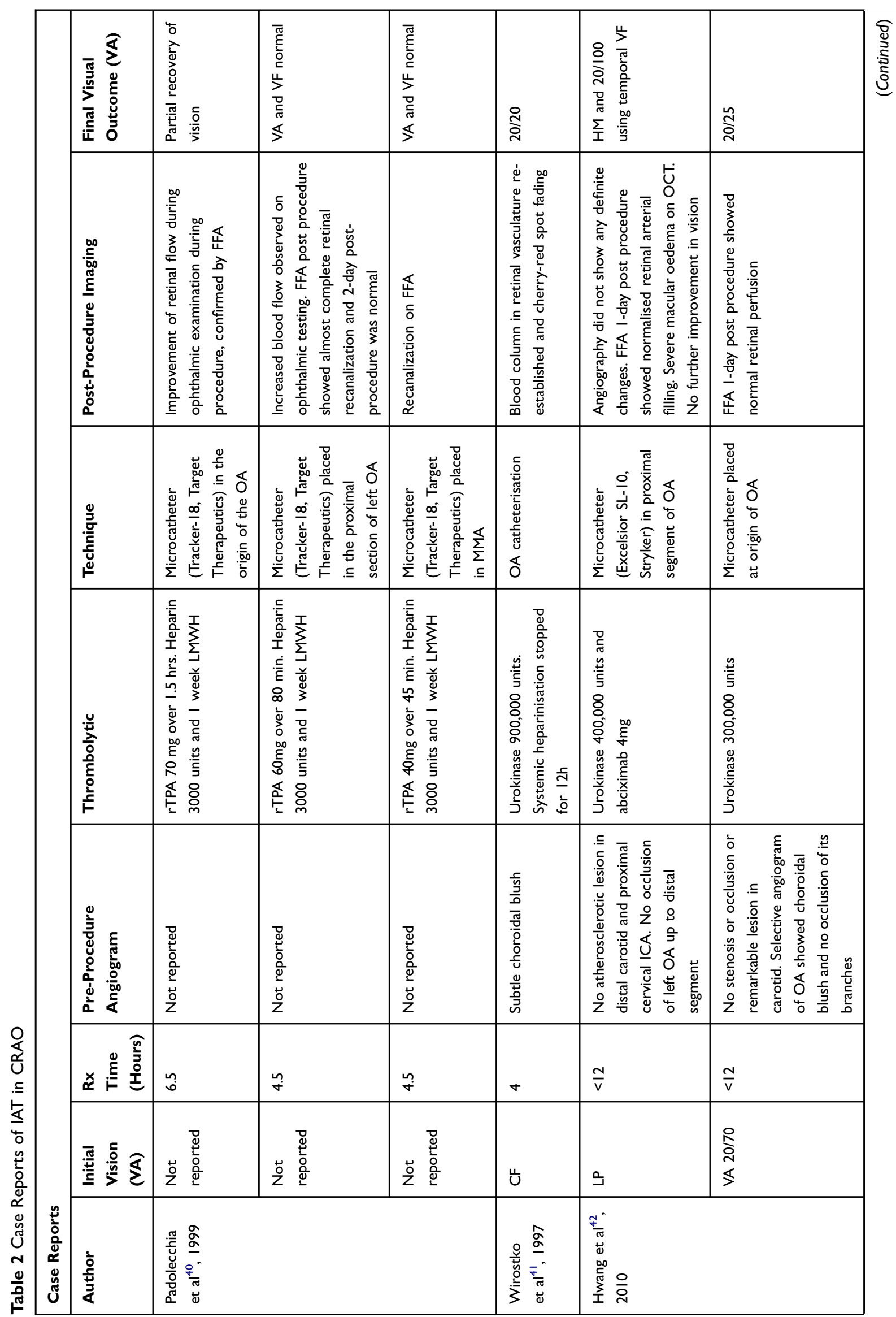




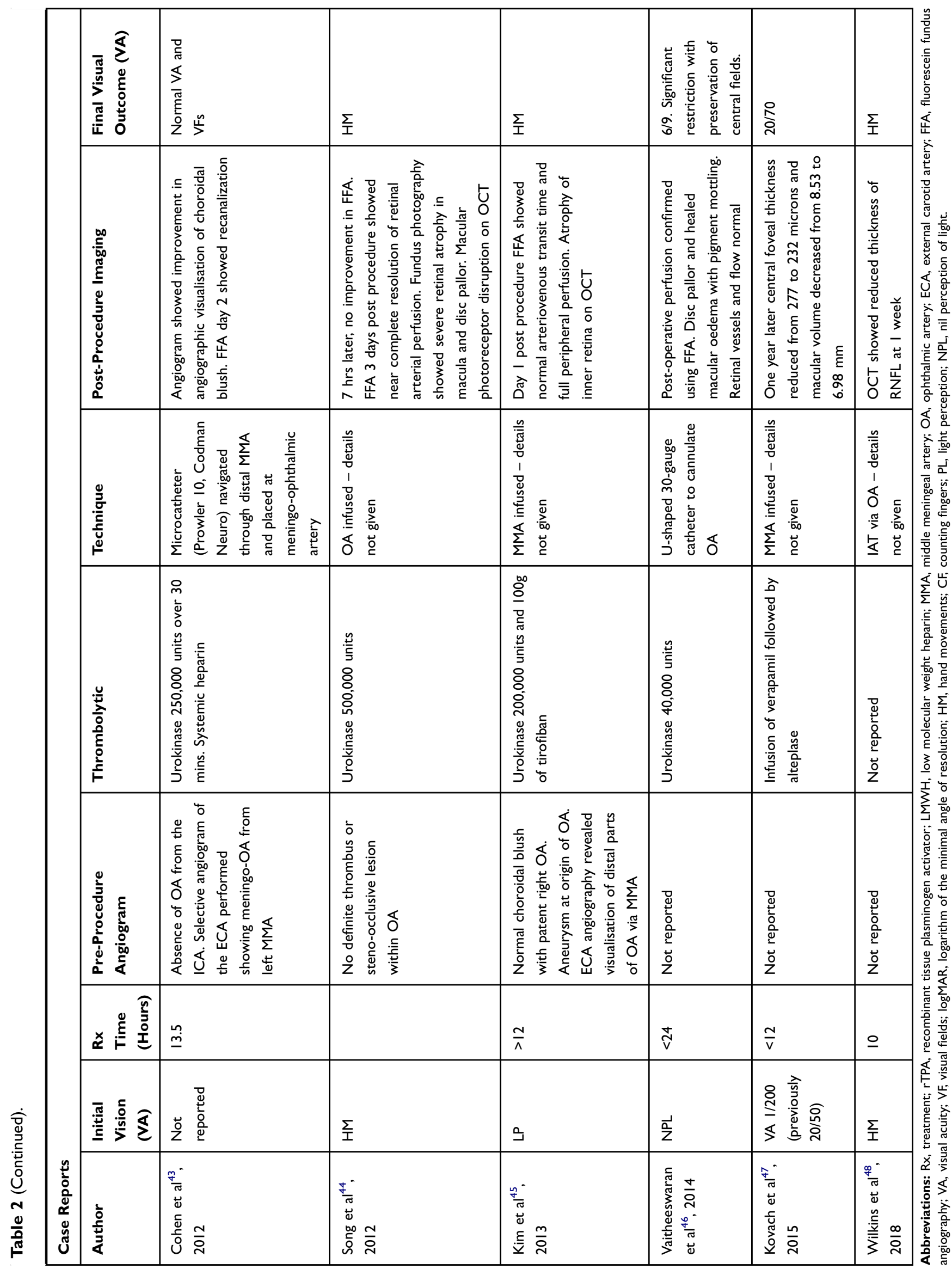




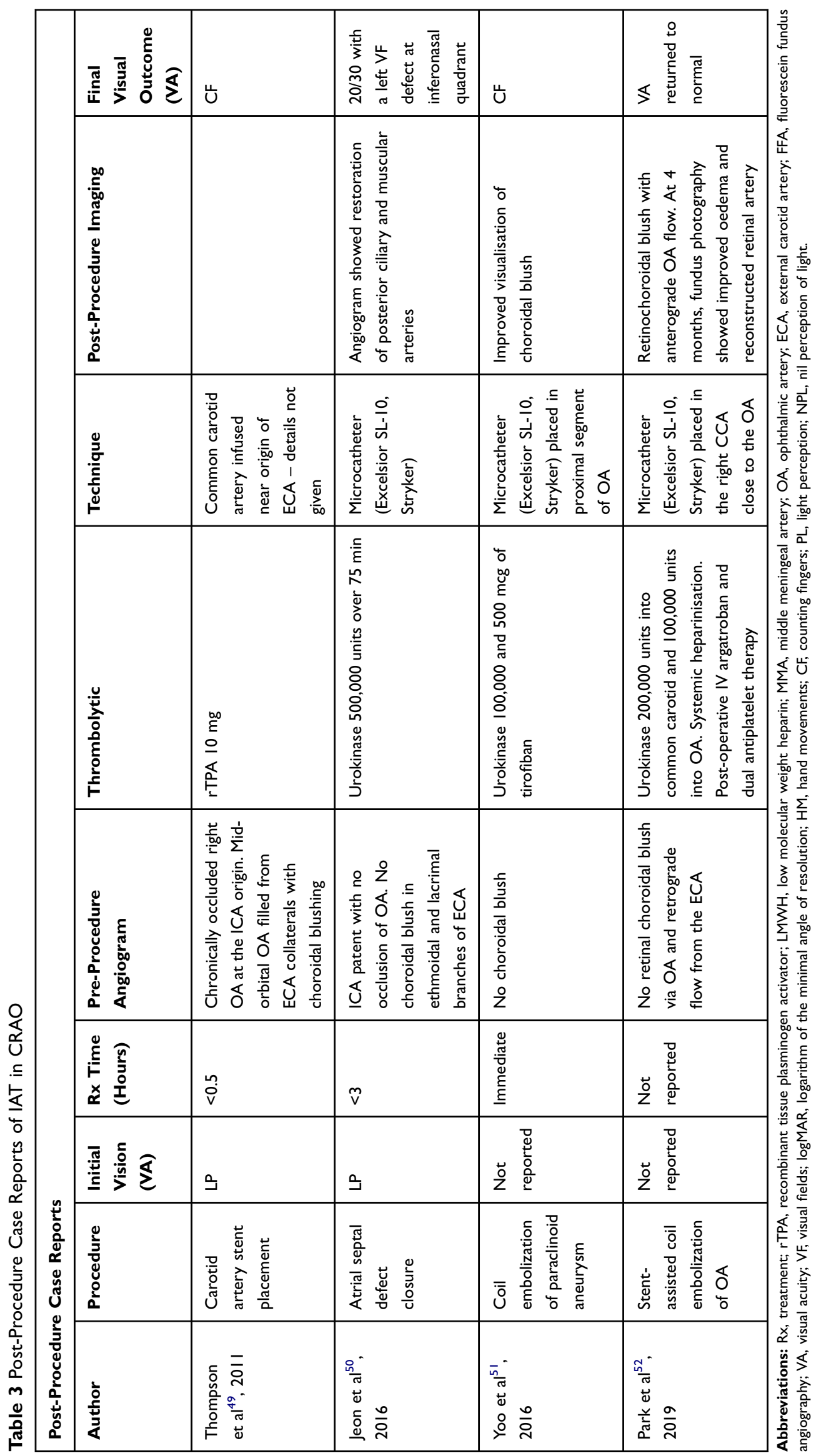




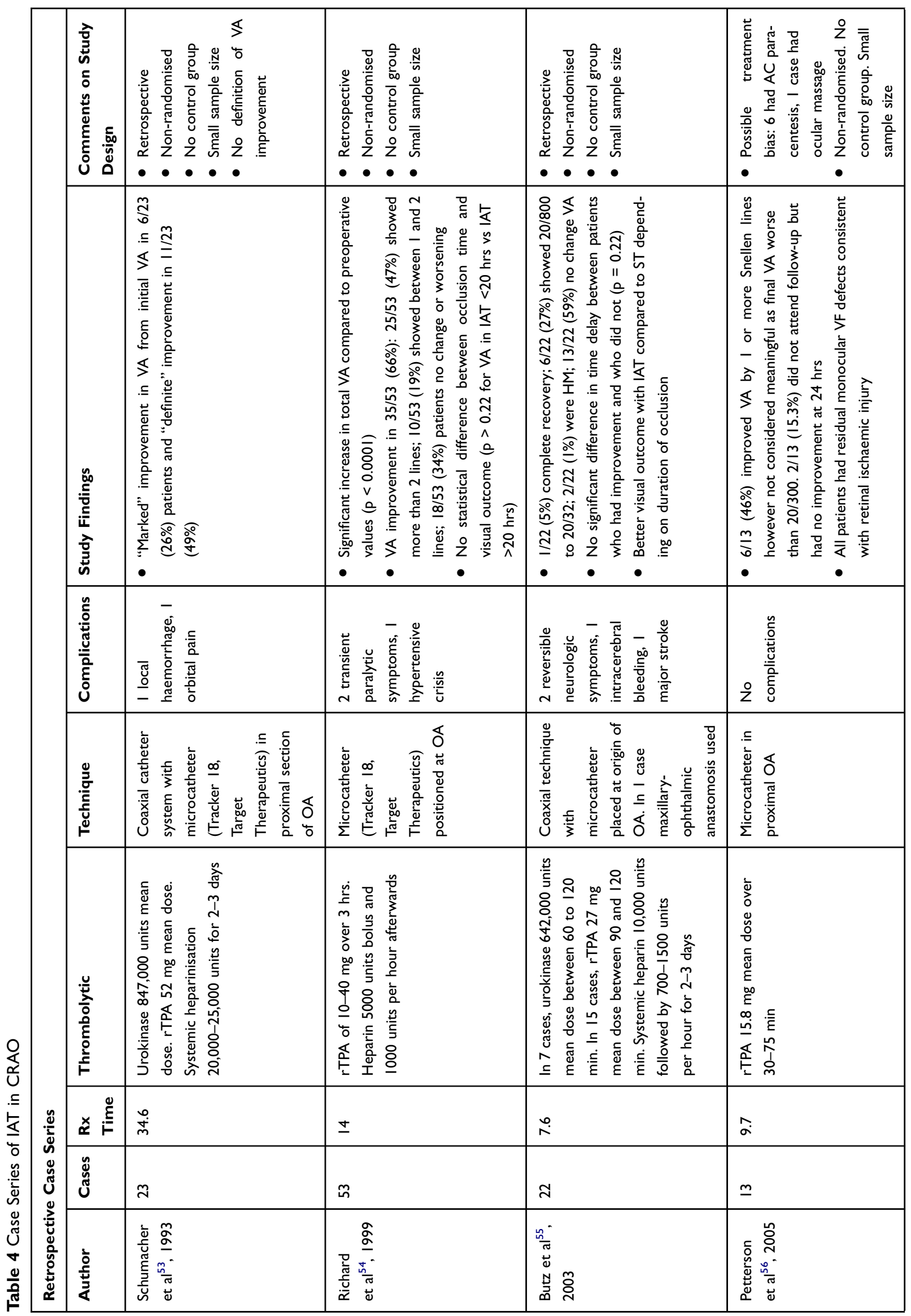




\begin{tabular}{|c|c|}
\hline 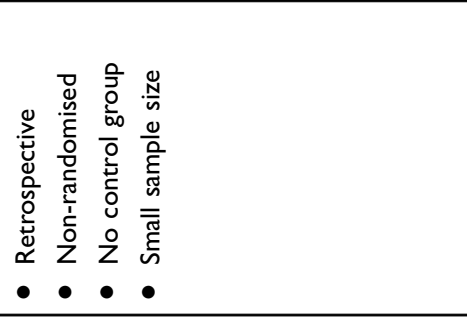 & 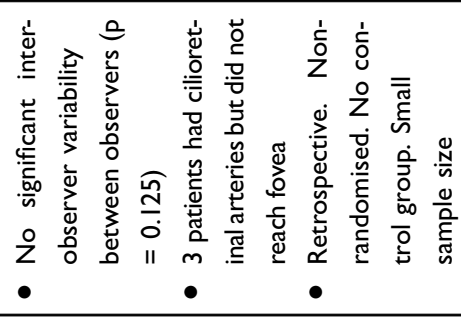 \\
\hline 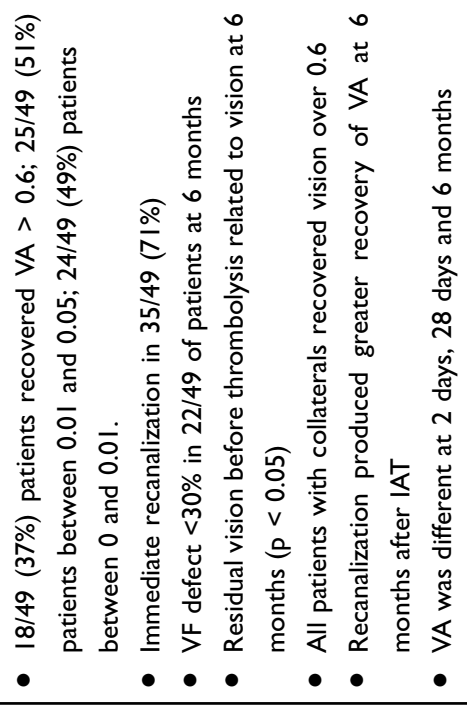 & 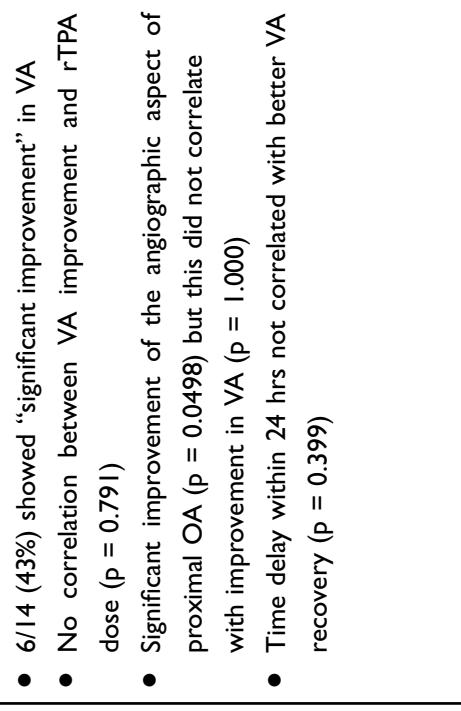 \\
\hline 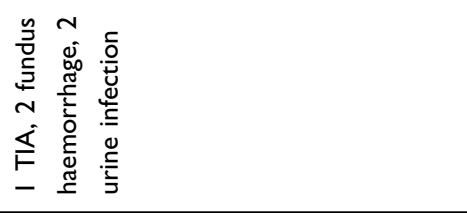 & z \\
\hline 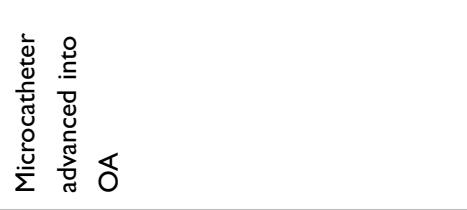 & 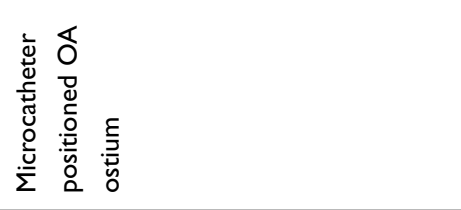 \\
\hline 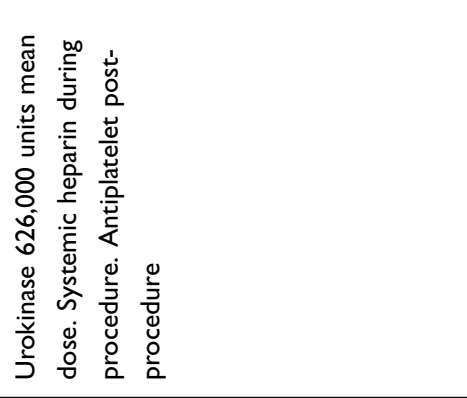 & 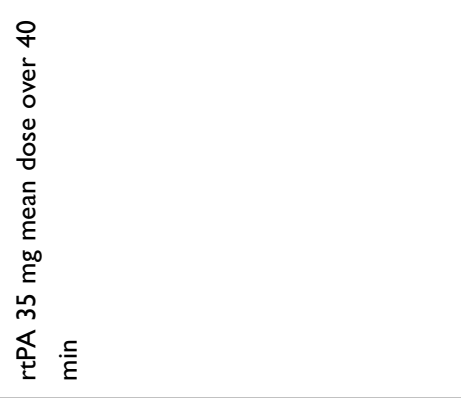 \\
\hline$\stackrel{v}{v}$ & $\infty$ \\
\hline g & \pm \\
\hline 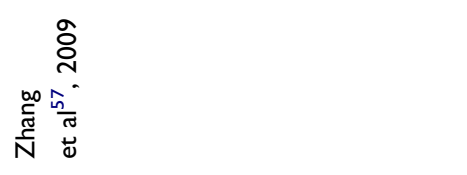 & 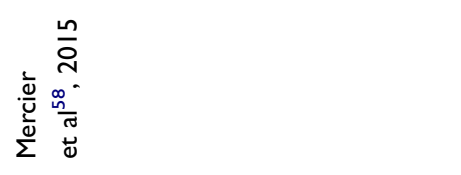 \\
\hline
\end{tabular}


administered were urokinase with a mean dose range of 642,000 to 847,000 units and rTPA with a mean dose range of 15.8 to $52 \mathrm{mg}$. Some authors gave additional systemic heparinization or antiplatelet therapy.

\section{Complications}

There were complications in 14 out of 174 patients (8\%), however, only 2 were major: 1 intracerebral bleed and 1 major stroke.

\section{Post-Procedure Case Series}

One case series was found on an iatrogenic cause for CRAO: Kim et $\mathrm{al}^{59}$ reported on 7 patients who developed CRAO after cosmetic facial filler injection: 3 autologous fatinjections and 4 hyaluronic acid. Urokinase, mean dose 193,000 units, was administered via microcatheter (Excelsior SL-10, Stryker) in the proximal OA to the 3 patients with suspected fat embolism and hyaluronidase, mean dose 3050 units, in the 4 patients post-hyaluronidase injection on average $3.8 \mathrm{hrs}$ after the onset of symptoms. None of these made any visual recovery and all were NPL despite recanalization in 2 patients. There were no complications.

\section{Case-Control Studies}

Five retrospective case-control studies were identified which studied IAT in 194 patients $^{10,12,60-62}$ (Table 5). Once again, different definitions of visual improvement were used: VA $>0.3 \log \mathrm{MAR}, \mathrm{VA}>0.6$, improvement in 1 line on Snellen compared to initial VA and assignment of numerical values to VA. One study ${ }^{12}$ did not provide a definition of VA improvement and described "distinct" and "partial" improvement in VA.

\section{Improvement in VA and Time to Treatment}

Three studies found a statistically significant improvement in visual outcome after IAT vs standard therapy, and the other 2 noted an effect in subgroup analysis. Two studies ${ }^{10,60}$ did not find a statistical significance between earlier time to treatment and visual outcome however patients were seen within 4 hrs and 6 hrs of symptom onset within these studies. The largest case-control study looked at 178 patients: Schmidt et $\mathrm{a}^{12}$ found that $77 \%$ of patients treated within 6 hrs had a distinct or partial improvement of VA compared to $53 \%$ in those treated between 6 and $14 \mathrm{hrs}$.

\section{Classification and Embolus Composition}

Schmidt et $\mathrm{al}^{12}$ excluded patients with cilioretinal arteries and arteritic CRAO was excluded in 4 studies. ${ }^{10,60,62}$ Embolus composition was not considered in any of the studies.

\section{Technique and Dosage}

Similar techniques of microcatheter placement within the proximal OA were performed. Urokinase was administered in most studies ranging from 200,000 to $1,300,000$ units and rTPA was delivered in $3 \mathrm{mg}$ aliquots until a visual improvement or maximal dose was achieved. Different doses of systemic heparinization or antiplatelet therapy were also administered.

\section{Complications}

There were complications in 25 out of 178 patients (14\%) who underwent IAT: $6 / 25$ patients suffered a TIA and 2/25 suffered ischaemic strokes of which no patient had permanent disability. There were no cases of intracranial haemorrhage.

\section{Randomised Control Trial: European Assessment Group for Lysis in the Eye (EAGLE) Study}

The EAGLE study was a prospective, randomised, controlled, multicentre clinical trial on the efficacy of IAT versus standard treatment (ST) on best-corrected VA. The study had inclusion criteria to target NA-CRAO with symptoms of $<20$ hrs. Patients in the control group had the same ST protocol and patients who had IAT received this through a microcatheter in the OA, or if this was technically not possible due to occlusion or stenosis, through the external carotid artery using the collaterals to the OA. Heparin was used with monitoring of activated clotting time during the procedure. RTPA was used for thrombolysis up to a maximum of $50 \mathrm{mg}$ with ophthalmic testing of VA and fundoscopy at 15 min intervals. Patients in both groups received the same post-procedure therapy of heparin and acetylsalicylic acid.

The primary end point was change in best-corrected VA 1 month after therapy compared with before therapy and clinically significant visual improvement was defined as a decrease in $\log$ MAR of $\geq 0.3$. Patients were randomised and a power calculation of $80 \%$ using an alpha level of 0.05 was carried out. An intention to treat analysis was also used. The trial was stopped after the first interim analysis by the Data Monitoring Committee and analysis was performed on 42 patients who underwent IAT and 40 patients who had ST.

The trial found no difference in change in $\log$ MAR between ST and IAT (ST vs IAT 0.004; 95\% confidence interval (CI) -0.236 to $0.245 ; \mathrm{p}=0.69$ ). There was no difference between change in $\operatorname{logMAR}$ and baseline bestcorrected VA (ST vs IAT $-0.01 ; 95 \%$ CI -0.255 to 0.234 ; 


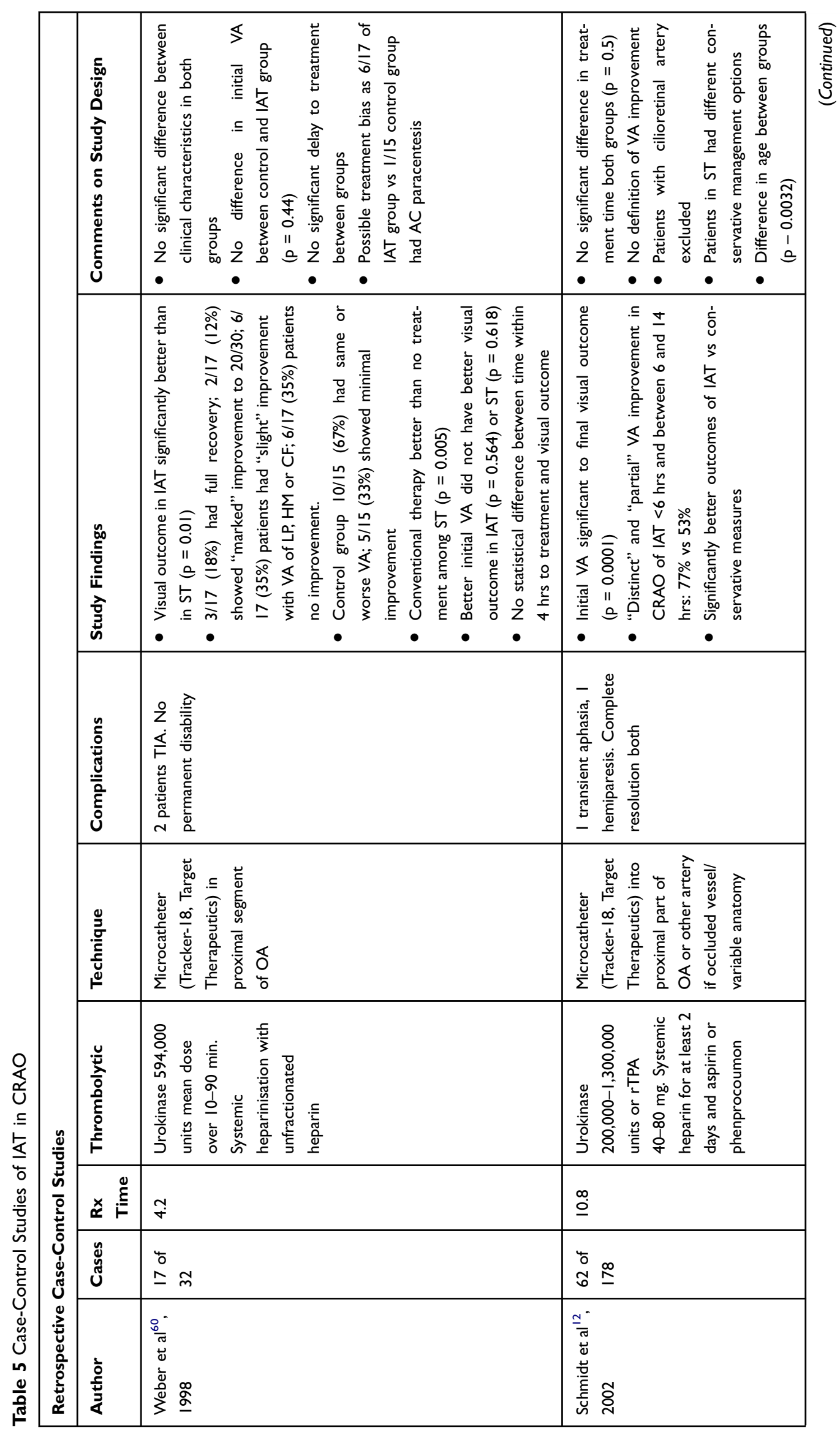




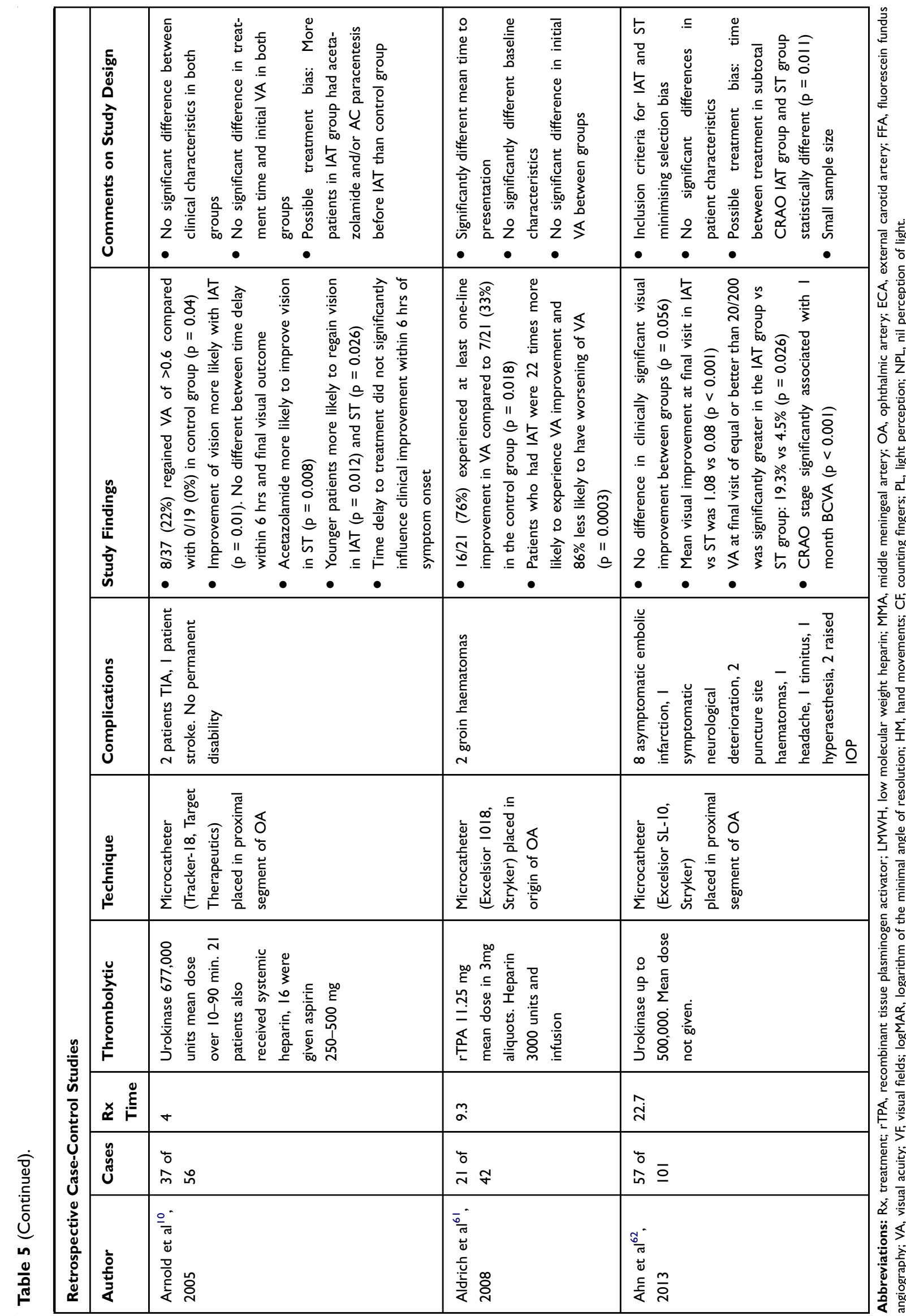


$\mathrm{p}=0.93)$. There was a statistically significant mean improvement in best-corrected VA compared with the baseline VA in both groups: $60 \%$ in ST and $57.1 \%$ in IAT. A better visual prognosis was detected in patients with a shorter time to treatment. There was 1 cerebral and 1 cerebellar haemorrhage within the IAT group. Both these patients made a full recovery. Twelve other patients experienced at least 1 minor adverse reaction resulting in an overall complication rate of $37.1 \%$ within the IAT group.

The trial had inclusion and exclusion criteria that excluded confounding factors such as patients with arteritic CRAO and cilioretinal artery sparing, however, these criteria were breached in 9 patients. It has been argued that the study protocol was vague and may have been interpreted differently by different study centres resulting in unidentical data. ${ }^{14}$ Randomisation, though performed, was not followed: 3 patients randomised to ST received only part of ST and 4 patients randomised to IAT underwent ST due to technical failure of IAT. In another 3 cases, patients underwent ST instead of IAT. Additionally, blinding was not performed which could have resulted in observer bias of the primary end point. The primary end point was also not measured in 5 patients. Consequently, the final study group consisted of 31 patients who underwent IAT and 30 patients who had $\mathrm{ST}$ and due to the low recruitment rate, a conditional power analysis was performed on these patients assuming the remaining patients who were not recruited would have the same trend in results. Within the treatment group, patients with CRAO up to $12 \mathrm{hrs}$ after onset were included to ensure the sample size was sufficient to power the study, and in some patients, treatment was not administered until $23 \mathrm{hrs}$ after the onset of symptoms. Ironically, the same authors reported a better visual outcome when thrombolysis was performed earlier. ${ }^{10,12}$ These flaws in study design and an increased time to treatment may have prevented the identification of a true effect.

\section{Discussion}

A limitation of this review is that only articles in English have been included and the authors are aware that articles in German and other languages form a relevant part of the existing literature. Regardless there are many limitations to the available literature. Due to the retrospective and nonrandomized nature of the studies, selection bias is an important source of error. Additionally, the studies are single centre with small sample sizes. There is likely an element of publication bias with favourable results being published and thus the effects of thrombolysis are potentially overestimated. Equally, complications due to IAT are likely underestimated.

The findings of these studies generally favour an effect towards IAT. A meta-analysis by Beatty et $\mathrm{al}^{11}$ in 2007 of the available literature found that $34.9 \%(n=$ 87) of patients who underwent thrombolysis had obvious improvement in VA and the results of thrombolysis appeared better than the visual recovery with conservative measures or the natural history of the condition. Additionally, a meta-analysis by Page et $\mathrm{al}^{63}$ found a pooled odds ratio of 3.32 to 3.41 of the controlled studies which was reduced to $2.52-2.65$ by the addition of the EAGLE study - still considerably in favour of IAT. However, different outcome measures were used to assess the effectiveness of IAT varying from descriptive improvement in VA from initial VA to quantitative analysis using $\log$ MAR. The EAGLE trial, despite its flaws, also did not find any clinical significance.

Though improvement in VA was observed, it is important to consider whether this is meaningful. Petterson et $\mathrm{al}^{56}$ found that $46 \%$ of patients had at least 1 line of improvement of Snellen VA though this was not considered meaningful as all patients had a final VA worse than 20/300. The number of patients who achieved an improvement of $\geq 0.3$ $\log$ MAR is significantly lower (Table 6).

In addition, VA only assesses the function of the fovea whereas VFs are required to evaluate the remainder of the retinal function; VFs were not performed in the majority of patients. Post-procedure FFA was also not performed regularly. FFA or direct visualisation of improvement with angiography was reported in the majority of case reports (9 out of 12) and recanalization was seen in the majority of these patients. A limitation of this is that improvement of retinal perfusion on ophthalmic examination can occur without visualisation of recanalization due to the small size of the CRA on angiogram. ${ }^{42}$ Additionally, movement of emboli resulting in spontaneous reperfusion has been reported in up to $69 \%$ of emboli at 1 month post-onset of CRAO. ${ }^{65}$ However, this has to be interpreted with caution as $44 \%$ of these patients had IAT which could have a major effect on movement. Late complete reperfusion was also seen in 33\% nonmoving emboli and late incomplete reperfusion in $67 \%$. The timing of post-IAT imaging is therefore relevant to differentiate between a true effect of thrombolysis or recanalization due to the natural history of the condition. 
Table 6 Summary of Papers with Level of Evidence ${ }^{64}$ and Patients Achieving an Improvement of $\geq 0.3$ logMAR

\begin{tabular}{|c|c|c|c|}
\hline Level of Evidence & Paper & VA $\geq 0.3 \log M A R$ with IAT & $\begin{array}{l}\text { VA } \geq 0.3 \log \text { MAR } \\
\text { in Controls }\end{array}$ \\
\hline $\begin{array}{l}\text { Ia: Systematic reviews (with homogeneity) of randomized } \\
\text { controlled trials }\end{array}$ & - & - & - \\
\hline $\begin{array}{l}\text { Ib: Individual randomized controlled trials (with narrow } \\
\text { confidence interval) }\end{array}$ & - & - & - \\
\hline Ic: All or none randomized controlled trials & Schumacher et al (2010) & $24 / 40$ & $24 / 42$ \\
\hline $\begin{array}{l}\text { 2a: Systematic reviews (with homogeneity) of cohort } \\
\text { studies }\end{array}$ & - & - & - \\
\hline $\begin{array}{l}\text { 2b: Individual cohort study or low quality randomized } \\
\text { controlled trials (eg }<80 \% \text { follow-up) }\end{array}$ & - & - & - \\
\hline 2c: "Outcomes" Research; ecological studies & - & - & - \\
\hline $\begin{array}{l}\text { 3a: Systematic review (with homogeneity) of case-control } \\
\text { studies }\end{array}$ & - & - & - \\
\hline 3b: Individual case-control study & $\begin{array}{l}\text { Weber et al (1998) } \\
\text { Schmidt et al (2002) } \\
\text { Arnold et al (2005) } \\
\text { Aldrich et al (2008) } \\
\text { Ahn et al (2013) }\end{array}$ & $\begin{array}{l}5 / 17 \\
\text { Not given } \\
8 / 37 \\
7 / 21 \\
21 / 57\end{array}$ & $\begin{array}{l}0 / 15 \\
\text { Not given } \\
0 / 19 \\
\text { Not given } \\
10 / 44\end{array}$ \\
\hline $\begin{array}{l}\text { 4: Case series (and poor-quality cohort and case-control } \\
\text { studies) }\end{array}$ & $\begin{array}{l}\text { Schumacher et al (1993) } \\
\text { Richard et al (1999) } \\
\text { Butz et al (2003) } \\
\text { Petterson et al (2005) } \\
\text { Zhang et al (2009) } \\
\text { Mercier et al (2015) }\end{array}$ & $\begin{array}{l}4 / 23 \\
11 / 53 \\
2 / 22 \\
0 / 9 \\
18 / 49 \text { (initial VA not given) } \\
4 / 14\end{array}$ & $\begin{array}{l}- \\
- \\
- \\
- \\
- \\
-\end{array}$ \\
\hline 5: Expert opinion & $\begin{array}{l}\text { Padolecchia et al (1999) } \\
\text { Wirostko et al (1997) } \\
\text { Hwang et al (2010) } \\
\text { Cohen et al (20I2) } \\
\text { Song et al (20I2) } \\
\text { Kim et al (20I3) } \\
\text { Vaitheeswaran et al (20I4) } \\
\text { Kovach et al (20I5) } \\
\text { Wilkins et al (2018) }\end{array}$ & $\begin{array}{l}\text { Not given } \\
1 / 1 \\
1 / 2 \\
\text { Not given } \\
0 / 1 \\
0 / 1 \\
1 / 1 \\
0 / 1 \\
0 / 1\end{array}$ & $\begin{array}{l}- \\
- \\
- \\
- \\
- \\
- \\
- \\
-\end{array}$ \\
\hline
\end{tabular}

Despite its limitations, post-IAT imaging needs to be performed early, if not immediately, to allow for this comparison to be made.

It is important to consider confounding between IAT benefit with the natural history of visual improvement. Hayreh et $\mathrm{al}^{15}$ showed there was VA improvement in $82 \%$ of patients with transient CRAO and $22 \%$ in NACRAO, the majority of which occurs within 7 days of symptom onset. Moreover, $6.5 \%$ of patients recovered to $20 / 20,16 \%$ to $20 / 40$ and $29 \%$ achieved $20 / 200$ or better.
Thus, some of the benefits observed in these studies is likely due to the natural improvement in visual function.

There was variation in studies between the significance of time to treatment and its effect on visual outcome. The results of the case reports show that all 3 patients who had IAT within $6 \mathrm{hrs}$ recovered normal VA and 2 had normal VFs; 3 case series did not find a statistical significance between time delay and improved VA; 2 case-control studies did not find a statistically significant improvement with shorter time however patients were seen within 4 and 
$6 \mathrm{hrs}$ of symptom onset and a non-significant trend towards better visual outcome was noted in patients treated within 4 hrs. $^{10}$ Schmidt et $\mathrm{al}^{12}$ found that $77 \%$ of patients treated within $6 \mathrm{hrs}$ had a distinct or partial improvement of VA compared to $53 \%$ in those treated between 6 and 14 hrs. In the EAGLE trial, the mean time to IAT treatment was approximately $13 \mathrm{hrs}$. This flaw in study design and increased time to treatment may have prevented the identification of a true effect.

CRAO classification was taken into account by some of the studies: Arteritic CRAO was excluded in 6/12 case reports, 2/6 case series, 4/5 case-controls studies. Given the serious nature of GCA, it was likely excluded in the other studies however this was not published. However, the presence of cilioretinal arteries was largely unaccounted for. This is an important factor as it is a common occurrence which may affect the improvement in VA from the preservation of blood supply to the macula.

Embolus composition was not taken into account by any of the studies and may be an important factor with respect to response to thrombolysis. Understandably, this is difficult to assess and is not visible in many cases. Arruga et $\mathrm{al}^{19}$ reported that $57 \%$ of emboli were made of cholesterol, 11\% platelet-fibrin and approximately $9 \%$ calcific. As such, the scientific basis for the use of thrombolysis was refuted by Hayreh ${ }^{66}$ as emboli formed of cholesterol or calcified material cannot be dissolved by thrombolytics and thus it would only be applicable in approximately $11 \%$ of patients with a platelet-fibrin clot. ${ }^{19}$ In addition, he argued that thrombolytic agents were unlikely to reach the thrombus in adequate concentration when the CRA is fully occluded thus unable to dissolve the thrombus. ${ }^{66}$ In contrast to this, a more recent study by Cho et al $^{65}$ reported that platelet-fibrin emboli were the most common: $52 \%$ were platelet-fibrin, $40 \%$ cholesterol and $8 \%$ calcific thus thrombolysis may indeed have a role in the treatment of CRAO. Additionally, thrombolysis may be useful for the lysis of secondary stasis-induced thrombi ${ }^{54}$ and thus may be useful even in cases of cholesterol or calcific thrombi.

There was variation in IAT technique and treatment protocol. Investigators placed a microcatheter inserted into the proximal segment of the OA or through the ECA if this was technically challenging due to atherosclerosis or stenoocclusive disease. There was also heterogeneity in the thrombolytic agents used: urokinase, rTPA or alteplase, and dosages varied between the studies. In many cases, the thrombolytic dose was guided by ophthalmic examination and thrombolysis stopped when the improvement of VA was noted or maximum dose received. Different regimes of postprocedure anticoagulation or antiplatelet therapy were also administered. There were variations in standard treatment delivered to both control group patients and those who underwent IAT, with some patients in the latter having more measures leading to potential treatment bias. These variations make it difficult to make comparisons and identify the optimal dose of thrombolytics.

Thrombolysis has a risk of serious systemic complications including TIA, stroke and intracerebral haemorrhage. A number of minor complications were also experienced by patients such as headache and dizziness. ${ }^{13}$ The overall major complication rate was not as high as expected. Due to the potential of publication bias, the complication rate is likely underestimated. Combining the studies, there were major complications in 12/399 (3.0\%) patients who underwent IAT: 3 intracranial bleed, 3 stroke and 6 TIAs. This complication rate is considerably higher within the EAGLE trial in which there were 2 intracranial haemorrhages in 31 patients $(6.5 \%)$ who underwent IAT. It has been argued that this higher complication rate may have been due to undetected stroke due to concern over visual loss or expansion of a silent infarct. ${ }^{67}$ In addition, studies have shown that up to $25 \%$ of patients have silent infarcts on $\mathrm{MRI}^{38}$ and thus baseline brain imaging may have detected these and consequently reduced the complication rate within the trial. Additionally, patients had different regimens of systemic heparinisation which in itself increases the risk of haemorrhage.

The procedure of IAT also contributes towards a risk of embolic infarction but this was found to be comparable to silent infarction following diagnostic angiography and intervention and thus there is no additional risk. ${ }^{68}$ This was thought to be due to distal emboli directly related to the procedure. In many cases, management was initiated by administering an additional dose of thrombolytic through the microcatheter resulting in resolution of neurological deficit. It is important not to dismiss silent infarction as it has been associated with an increased risk of dementia and cognitive decline. ${ }^{69}$

\section{Future Prospects}

It was reported by Beatty et $\mathrm{al}^{11}$ that any treatment that would provide even a marginally better visual outcome than conventional management would be a welcome advance. IAT may provide this however current literature is not enough to support this notion. Further investigation may shed more 
light on this topic. This should ideally be a large, multicentre, prospective RCT to compare the efficacy of IAT with no intervention in patients presenting within a few hours of onset of symptoms with robust inclusion and exclusion criteria to assess patients according to the type of CRAO using the same technical procedure and comparable doses of thrombolytic agents with immediate post-procedural imaging to identify recanalization as well as recording of VFs. This is a difficult task - one which is unlikely to ever occur and it faces the same tests as the EAGLE trial in difficulties with the recruitment of patients, particularly within an acute time frame. Other challenges include the lack of public education on CRAO resulting in a delayed presentation, complications of thrombolysis as well as cost. Additionally, the technique of IAT is technically challenging and can likely only be performed in tertiary centres with the resources for early diagnosis, administration of IAT and monitoring thereafter. Current healthcare infrastructure is not developed to perform this routinely and it is largely confined to tertiary centres.

Novel management options for acute ischaemic stroke may provide a glimpse into potential treatment options for CRAO. Mechanical thrombectomy with or without thrombolysis has been shown to be effective in select patients with acute anterior stroke in several multicentre RCTs. ${ }^{17}$ Similarly, Nd:YAG laser embolectomy has been performed within retinal vessels to dislodge emboli. A metaanalysis by Man et $\mathrm{al}^{30}$ of Nd:YAG laser embolectomy found a statistically significant improvement in VA with a weighted mean change from 20/252 to 20/47. Surprisingly, visual improvement was similar regardless of time to treatment varying from under $4 \mathrm{hrs}$ up to 1 week. However, available literature is scarce and this meta-analysis included only 18 reports involving 61 patients, of which only 14 had CRAO. These patients showed some improvement however it is unclear whether this was significantly different to the natural history of the condition. The haemorrhage rate was $57 \%$ with moderatesevere haemorrhage in $26 \%$ of patients which in some cases prevented further laser due to obscuration of the embolus. Fifteen percent of patients also went on to have vitrectomy. Major limitations to this treatment are the significantly high complication rate and the fact that only visible emboli can be treated which as mentioned are rare.

More recently, a new technique of IAT has been practiced by Kadonosono et $\mathrm{al}^{70}$. This involved vitrectomy and injection of rTPA directly into the retinal artery using a microneedle. Due to this direct injection, a dose of only
$200 \mu \mathrm{g}$ was used. Thirteen patients underwent this technique and 12 patients recovered a VA of $>0.3 \operatorname{logMAR}$ with a mean improvement from 20/800 to 20/130. They observed complete reperfusion in 10 eyes. There was 1 massive vitreous haemorrhage requiring second surgery. Though these results are promising, this technique is again technically challenging and more studies are required. In the absence of proven successful treatment options in this important condition, new techniques such as this are encouraging.

\section{Conclusion}

CRAO is an important cause of visual loss that has a large impact on quality of life. ${ }^{71}$ Conservative treatment measures have not been shown to improve visual outcome in patients. There is a lack of large-scale clinical trials and current evidence is not sufficient to recommend IAT due to the variability of visual improvement within retrospective studies, heterogeneity in treatment regimens between studies and adverse effects associated with thrombolysis. Furthermore, despite multiple flaws, the EAGLE trial showed lack of effect in IAT vs conservative measures. In addition, many patients do not present early enough from the onset of symptoms to derive benefit. However, given the devastating nature of CRAO and the lack of efficacy of conservative measures, IAT may have a role in patients presenting early - particularly if they have monocular vision, after discussion of the risks and benefits. Further high-quality trials assessing the clinical efficacy of IAT may shed more light on this topic.

\section{Ethics Statement}

All figures are original and have not been reproduced from previously published sources. Consent was gained for the publication of all figures.

\section{Disclosure}

The authors report no conflicts of interest in this work.

\section{References}

1. von Graefes A. Ueber Embolie der Arteria centralis retinae als Ursache plötzlicher Erblindung. Archiv Ophthalmol. 1859;5: 136-157.

2. Hazin R, Dixon JA, Bhatti MT. Thrombolytic therapy in central retinal artery occlusion: cutting edge therapy, standard of care therapy, or impractical therapy? Curr Opin Ophthalmol. 2009;20(3):210-218. doi:10.1097/ICU.0b013e328329b5d5

3. Leavitt JA, Larson TA, Hodge DO, Gullerud RE. The incidence of central retinal artery occlusion in Olmsted County, Minnesota. Am $J$ Ophthalmol. 2011;152(5):820-823.e2. doi:10.1016/j.ajo.2011.05. 005 
4. Fraser SG, Adams W. Interventions for acute non-arteritic central retinal artery occlusion. Cochrane Database Syst Rev. 2009;(1): Cd001989.

5. Varma DD, Cugati S, Lee AW, Chen CS. A review of central retinal artery occlusion: clinical presentation and management. Eye (Lond). 2013;27(6):688-697. doi:10.1038/eye.2013.25

6. Sharma RA, Dattilo M, Newman NJ, Biousse V. Treatment of nonarteritic acute central retinal artery occlusion. Asia-Pac j Ophthalmol. 2018;7(4):235-241. doi:10.22608/APO.201871

7. Annonier P, Sahel J, Wenger JJ, Rigolot JC, Foessel M, Bronner A. Local fibrinolytic treatment in occlusions of the central retinal artery. J Fr Ophtalmol. 1984;7(11):711-716.

8. Chen CS, Lee AW, Campbell B, et al. Study of the efficacy of intravenous tissue plasminogen activator in central retinal artery occlusion. Int $j$ Stroke. 2011;6(1):87-89. doi:10.1111/j.17474949.2010.00545.x

9. Page PS, Cambon AC, James RF. Visual improvement after intra-arterial thrombolysis for central retinal artery occlusion does not correlate with time to treatment. Interventional Neurol. 2016;5 (3-4):131-139. doi:10.1159/000446853

10. Arnold M, Koerner U, Remonda L, et al. Comparison of intra-arterial thrombolysis with conventional treatment in patients with acute central retinal artery occlusion. J Neurol Neurosurg Psychiatry. 2005;76 (2):196-199. doi:10.1136/jnnp.2004.037135

11. Beatty S, Au Eong KG. Local intra-arterial fibrinolysis for acute occlusion of the central retinal artery: a meta-analysis of the published data. $\mathrm{Br} J$ Ophthalmol. 2000;84(8):914-916. doi:10.1136/ bjo.84.8.914

12. Schmidt DP, Schulte-Monting J, Schumacher M. Prognosis of central retinal artery occlusion: local intraarterial fibrinolysis versus conservative treatment. Am j Neuroradiol. 2002;23(8): 1301-1307.

13. Schumacher M, Schmidt D, Jurklies B, et al. Central retinal artery occlusion: local intra-arterial fibrinolysis versus conservative treatment, a multicenter randomized trial. Ophthalmology. 2010;117 (7):1367-75.e1. doi:10.1016/j.ophtha.2010.03.061

14. Hayreh SS. Comment re: multicenter study of the European Assessment Group for Lysis in the Eye (EAGLE) for the treatment of central retinal artery occlusion: design issues and implications. Graefe's Archiv Clin Exp Ophthalmol. 2007;245(3):464-6; author reply 7-70. doi:10.1007/s00417-006-0473-5

15. Hayreh SS, Zimmerman MB. Central retinal artery occlusion: visual outcome. Am J Ophthalmol. 2005;140(3):376-391. doi:10.1016/j. ajo.2005.03.038

16. Hayreh SS, Zimmerman MB. Fundus changes in central retinal artery occlusion. Retina. 2007;27(3):276-289. doi:10.1097/01.iae.0000238095. $97104.9 \mathrm{~b}$

17. Chancellor BK, Ishida K. New standards of care in ischemic stroke. J Neuro-Ophthalmol. 2017;37(3):320-331. doi:10.1097/WNO.0000000 000000449

18. Hayreh SS, Podhajsky PA, Zimmerman MB. Retinal artery occlusion: associated systemic and ophthalmic abnormalities. Ophthalmology. 2009;116(10):1928-1936. doi:10.1016/j.ophtha.2009.03.006

19. Arruga J, Sanders MD. Ophthalmologic findings in 70 patients with evidence of retinal embolism. Ophthalmology. 1982;89(12):1336-1347. doi:10.1016/S0161-6420(82)34626-6

20. Singh S, Dass R. The central artery of the retina. I. Origin and course. Br J Ophthalmol. 1960;44:193-212. doi:10.1136/bjo.44.4.193

21. Hayreh SS, Kolder HE, Weingeist TA. Central retinal artery occlusion and retinal tolerance time. Ophthalmology. 1980;87(1):75-78. doi:10.1016/S0161-6420(80)35283-4

22. Hayreh SS, Jonas JB. Optic disk and retinal nerve fiber layer damage after transient central retinal artery occlusion: an experimental study in rhesus monkeys. Am J Ophthalmol. 2000;129(6):786-795. doi:10. 1016/S0002-9394(00)00384-6
23. Schrag M, Youn T, Schindler J, Kirshner H, Greer D. Intravenous fibrinolytic therapy in central retinal artery occlusion: a patient-level meta-analysis. JAMA Neurol. 2015;72(10):1148-1154. doi:10.1001/ jamaneurol.2015.1578

24. David NJ, Norton EW, Gass JD, Beauchamp J. Fluorescein angiography in central retinal artery occlusion. Archiv Ophthalmol. 1967;77(5):619-629. doi:10.1001/archopht.1967.00980020621010

25. Falkenberry SM, Ip MS, Blodi BA, Gunther JB. Optical coherence tomography findings in central retinal artery occlusion. Ophthal Surg Lasers Imaging. 2006;37(6):502-505. doi:10.3928/1542887720061101-12

26. Limaye K, Wall M, Uwaydat S, et al. Is management of central retinal artery occlusion the next frontier in cerebrovascular diseases? J Stroke Cerebrovasc Dis. 2018;27(10):2781-2791. doi:10.1016/j.jstrokecerebrovasdis.2018.06.006

27. Justice J Jr., Lehmann RP. Cilioretinal arteries. A study based on review of stereo fundus photographs and fluorescein angiographic findings. Archiv Ophthalmol. 1976;94(8):1355-1358. doi:10.1001/ archopht.1976.03910040227015

28. Cugati S, Varma DD, Chen CS, Lee AW. Treatment options for central retinal artery occlusion. Curr Treat Options Neurol. 2013;15 (1):63-77. doi:10.1007/s11940-012-0202-9

29. Youn TS, Lavin P, Patrylo M, et al. Current treatment of central retinal artery occlusion: a national survey. J Neurol. 2018;265 (2):330-335. doi:10.1007/s00415-017-8702-x

30. Man V, Hecht I. Treatment of retinal artery occlusion using transluminal Nd: YAG laser: a systematic review and meta-analysis. Graefes Arch Clin Exp Ophthalmol. 2017;255(10):1869-1877. doi:10.1007/s00417-017-3777-8

31. Fibrinolytic Therapy Trialists' Collaborative Group. Indications for fibrinolytic therapy in suspected acute myocardial infarction: collaborative overview of early mortality and major morbidity results from all randomised trials of more than 1000 patients. Fibrinolytic Therapy Trialists' (FTT) Collaborative Group. Lancet. 1994;343 (8893):311-322.

32. National Institute of Neurological Disorders and Stroke rt-PA Stroke Study Group. Tissue plasminogen activator for acute ischemic stroke. $N$ Engl J Med. 1995;333(24):1581-1587. doi:10.1056/NEJM199512 143332401

33. Biousse V, Calvetti O, Bruce BB, Newman NJ. Thrombolysis for central retinal artery occlusion. J Neuro-Ophthalmol. 2007;27 (3):215-230. doi:10.1097/WNO.0b013e31814b1f66

34. Egan RA, Van Stavern R. Should patients with acute central retinal artery occlusion be treated with intra-arterial t-PA? J Neuro-Ophthalmol. 2015;35(2):205-209. doi:10.1097/WNO.0000000000000231

35. Schmidt D, Schumacher M, Wakhloo AK. Microcatheter urokinase infusion in central retinal artery occlusion. Am J Ophthalmol. 1992;113(4):429-434. doi:10.1016/S0002-9394(14)76167-7

36. Noble J, Weizblit N, Baerlocher MO, Eng KT. Intra-arterial thrombolysis for central retinal artery occlusion: a systematic review. $\mathrm{Br}$ J Ophthalmol. 2008;92(5):588-593. doi:10.1136/bjo.2007.133488

37. Rudkin AK, Lee AW, Chen CS. Ocular neovascularization following central retinal artery occlusion: prevalence and timing of onset. Eur J Ophthalmol. 2010;20(6):1042-1046. doi:10.1177/112067211002 000603

38. Helenius J, Arsava EM, Goldstein JN, et al. Concurrent acute brain infarcts in patients with monocular visual loss. Ann Neurol. 2012;72 (2):286-293. doi:10.1002/ana.v72.2

39. Avery MB, Magal I, Kherani A, Mitha AP. Risk of stroke in patients with ocular arterial occlusive disorders: a retrospective canadian study. J Am Heart Assoc. 2019;8(3):e010509. doi:10.1161/JAHA. 118.010509

40. Padolecchia R, Puglioli M, Ragone MC, Romani A, Collavoli PL. Superselective intraarterial fibrinolysis in central retinal artery occlusion. Am j Neuroradiol. 1999;20(4):565-567. 
41. Wirostko WJ, Pulido JS, Hendrix LE. Selective thrombolysis of central retinal artery occlusion without long-term systemic heparinization. Surg Neurol. 1998;50(5):408-410. doi:10.1016/ S0090-3019(97)00338-8

42. Hwang G, Woo SJ, Jung C, Park KH, Hwang JM, Kwon OK. Intraarterial thrombolysis for central retinal artery occlusion: two cases report. J Korean Med Sci. 2010;25(6):974-979. doi:10.3346/ jkms.2010.25.6.974

43. Cohen JE, Moscovici S, Halpert M, Itshayek E. Selective thrombolysis performed through meningo-ophthalmic artery in central retinal artery occlusion. J Clin Neurosci. 2012;19(3):462-464. doi:10.1016/j. jocn.2011.06.010

44. Song HB, Woo SJ, Jung CK, et al. Acute central retinal artery occlusion associated with livedoid vasculopathy: a variant of Sneddon's syndrome. Korean J Ophthalmol. 2013;27(5):376-380. doi:10.3341/kjo.2013.27.5.376

45. Kim YW, Woo SJ, Ahn J, Park KH, Kwon OK. Ophthalmic artery aneurysm: potential culprit of central retinal artery occlusion. Korean $J$ Ophthalmol. 2013;27(6):470-473. doi:10.3341/kjo.2013.27.6.470

46. Vaitheeswaran K, Kaur P, Garg S, Nadar M. Optic canal decompression and direct ophthalmic artery fibrinolysis for traumatic optic neuropathy with central retinal artery occlusion. Neuroophthalmology. 2014;38 (3):127-130. doi:10.3109/01658107.2013.874456

47. Kovach JL, Mason B. Visual recovery and OCT evolution following central retinal artery occlusion treated with intra-arterial verapamil and alteplase infusion. Ophthalmic Surg Lasers Imaging Retina. 2015;46(1):77-79. doi:10.3928/23258160-20150101-13

48. Wilkins CS, McCabe K, Deobhakta A, Chelnis J. Central retinal artery occlusion secondary to Barlow's disease. Am $j$ Ophthalmol Case Rep. 2018;10:249-252. doi:10.1016/j.ajoc.2018.03.003

49. Thompson EM, Egan RA, Nesbit GM, Hills WL. Rapid intra-arterial thrombolysis in stent-associated retinal artery occlusion. $J$ Vasc Interventional Radiol. 2011;22(3):410-412. doi:10.1016/j. jvir.2010.10.034

50. Jeon JP, Cho YD, Han MH. Intra-arterial thrombolysis of central retinal artery occlusion following percutaneous atrial septal defect closure. Catheter Cardiovasc Interv. 2016;88(1):157-160. doi:10.1002/ccd.v88.1

51. Yoo M, Jin SC. Intra-arterial thrombolysis for central retinal artery occlusion after the coil embolization of paraclinoid aneurysm. $J$ Cerebrovasc Endovasc Neurosurg. 2016;18(4):369-372.

52. Park H, Nakagawa I, Yokoyama S, et al. Central retinal artery thromboembolism without ophthalmic artery occlusion during stent-assisted coil embolization of ophthalmic artery aneurysm. PLoS One. 2019;121:77-82.

53. Schumacher M, Schmidt D, Wakhloo AK. Intra-arterial fibrinolytic therapy in central retinal artery occlusion. Neuroradiology. 1993;35 (8):600-605. doi:10.1007/BF00588405

54. Richard G, Lerche RC, Knospe V, Zeumer H. Treatment of retinal arterial occlusion with local fibrinolysis using recombinant tissue plasminogen activator. Ophthalmology. 1999;106(4):768-773. doi:10.1016/S0161-6420(99)90165-3

55. Butz B, Strotzer M, Manke C, Roider J, Link J, Lenhart M. Selective intraarterial fibrinolysis of acute central retinal artery occlusion. Acta Radiologica. 2003;44(6):680-684. doi:10.1046/j.1600-0455.2003.001 47.x
56. Pettersen JA, Hill MD, Demchuk AM, et al. Intra-arterial thrombolysis for retinal artery occlusion: the Calgary experience. Can j Neurol Sci. 2005;32(4):507-511. doi:10.1017/S0317167100004522

57. Zhang X, Ji X, Luo Y, et al. Intra-arterial thrombolysis for acute central retinal artery occlusion. Neurol Res. 2009;31(4):385-389. doi: $10.1179 / 174313209 X 444008$

58. Mercier J, Kastler A, Jean B, et al. Interest of local intra-arterial fibrinolysis in acute central retinal artery occlusion: clinical experience in 16 patients. J Neuroradiol. 2015;42(4):229-235. doi:10.1016/ j.neurad.2014.02.007

59. Kim YK, Jung C. Cerebral angiographic findings of cosmetic facial filler-related ophthalmic and retinal artery occlusion. J Korean Med Sci. 2015;30(12):1847-1855.

60. Weber J, Remonda L, Mattle HP, et al. Selective intra-arterial fibrinolysis of acute central retinal artery occlusion. Stroke. 1998;29 (10):2076-2079. doi:10.1161/01.STR.29.10.2076

61. Aldrich EM, Lee AW, Chen CS, et al. Local intraarterial fibrinolysis administered in aliquots for the treatment of central retinal artery occlusion: the Johns Hopkins Hospital experience. Stroke. 2008;39 (6):1746-1750. doi:10.1161/STROKEAHA.107.505404

62. Ahn SJ, Kim JM, Hong JH, et al. Efficacy and safety of intra-arterial thrombolysis in central retinal artery occlusion. Invest Ophthalmol Vis Sci. 2013;54(12):7746-7755. doi:10.1167/iovs.13-12952

63. Page PS, Khattar NK, White AC, et al. Intra-arterial thrombolysis for acute central retinal artery occlusion: a systematic review and meta-analysis. Front Neurol. 2018;9:76. doi:10.3389/fneur.2018.00076

64. Oxford Centre for Evidence-based Medicine. Levels of Evidence. 2009. Available from: https://www.cebm.net/2009/06/oxford-centreevidence-based-medicine-levels-evidence-march-2009/. Accessed December 5, 2019.

65. Cho KH, Ahn SJ, Cho JH, et al. The characteristics of retinal emboli and its association with vascular reperfusion in retinal artery occlusion. Invest Ophthalmol Vis Sci. 2016;57(11):4589-4598. doi:10.1167/iovs.16-19887

66. Hayreh SS. Intra-arterial thrombolysis for central retinal artery occlusion. $\mathrm{Br} J$ Ophthalmol. 2008;92(5):585-587. doi:10.1136/ bjo.2007.136481

67. Arthur A, Aaron S. Thrombolysis for artery occlusion. Ophthalmology. 2011;118(3):604; author reply -5 . doi:10.1016/j. ophtha.2010.10.042

68. Bendszus M, Koltzenburg M, Burger R, Warmuth-Metz M, Hofmann E, Solymosi L. Silent embolism in diagnostic cerebral angiography and neurointerventional procedures: a prospective study. Lancet. 1999;354 (9190):1594-1597. doi:10.1016/S0140-6736(99)07083-X

69. Vermeer SE, Prins ND, den Heijer T, Hofman A, Koudstaal PJ, Breteler MM. Silent brain infarcts and the risk of dementia and cognitive decline. $N$ Engl J Med. 2003;348(13):1215-1222. doi:10.1056/NEJMoa022066

70. Kadonosono K, Yamane S, Inoue M, Yamakawa T, Uchio E. Intraretinal arterial cannulation using a microneedle for central retinal artery occlusion. Sci Rep. 2018;8(1):1360. doi:10.1038/s41598-01819747-7

71. Vu HT, Keeffe JE, McCarty CA, Taylor HR. Impact of unilateral and bilateral vision loss on quality of life. $\mathrm{Br} J$ Ophthalmol. 2005;89 (3):360-363. doi:10.1136/bjo.2004.047498 


\section{Publish your work in this journal}

Clinical Ophthalmology is an international, peer-reviewed journal covering all subspecialties within ophthalmology. Key topics include: Optometry; Visual science; Pharmacology and drug therapy in eye diseases; Basic Sciences; Primary and Secondary eye care; Patient Safety and Quality of Care Improvements. This journal is indexed on PubMed

Submit your manuscript here: https://www.dovepress.com/clinical-ophthalmology-journal
Central and CAS, and is the official journal of The Society of Clinical Ophthalmology (SCO). The manuscript management system is completely online and includes a very quick and fair peer-review system, which is all easy to use. Visit http://www.dovepress.com/ testimonials.php to read real quotes from published authors. 